\title{
Conformations of the Pyranoid Sugars. IV. Infrared Absorption Spectra of Some Fully Acetylated Pyranoses
}

\author{
R. Stuart Tipson and Horace S. Isbell
}

(February 1, 1961)

\begin{abstract}
The infrared absorption spectra of twenty pyranose acetates in the range of 5000 to $250 \mathrm{~cm}^{-1}$ are reported. The conformation adopted by each of fourteen of the corresponding methyl glycopyranosides (or their acetates) had previously been assigned by us from a study of their infrared spectra. Analysis of the spectra revealed, for the pyranose acetates (as for the methyl glycopyranosides and their acetates), groups of absorption bands which showed a concerted shift on change of anomeric disposition. Assignment of conformation by the methods earlier developed indicated that, for most of the compounds examined, the conformation is the same for the pyranose acetate, methyl glycopyranoside, and acetylated methyl glycopyranoside of one anomer of a monosaccharide.

The following new assignments of conformation were made: the CA conformation for penta- $O$-acetyl- $\alpha$-L-xylo-hexulopyranose and hexa- $O$-acetyl- $\alpha$-D-gluco-heptulopyranose; and, possibly, either a non-chair conformation or a mixture of the $\mathrm{CA}$ and $\mathrm{CE}$ conformations for hexa- $O$-acetyl-L-glycero- $\beta$-D-gluco-heptopyranose and hexa- $O$-acetyl-D-glycero- $\beta$-D-galactoheptopyranose.
\end{abstract}

\section{Scope and Purpose of the Project}

As the inst objective of the present project, the infrared absorption spectra of a variety of fully acetylated pyranoses were recorded for use in identifying supposedly identical samples. The spectra of three of the compounds included in the present study were recorded by Kuhn $[1]^{1}$ for a limited range (1250 to $\left.667 \mathrm{~cm}^{-1}\right)$. In the following year, the spectra of 17 of the compounds were given (for the range of 5000 to $667 \mathrm{~cm}^{-1}$ ) by Isbell and coworkers in a privately circulated report [2] which was subsequently published [3]. Fifteen of the spectra obtained by these investigators were later discussed by Whistler and House [4], who noted certain bands in the range of 1170 to $931 \mathrm{~cm}^{-1}$. Next, Barker and coworkers [5] examined the spectra of two of Kuhn's compounds and of the enantiomorph of one, together with those of three others that are included in the present study. These workers [5] discussed some of the bands in the range of 960 to $730 \mathrm{~cm}^{-1}$, but the spectra were published in insufficient detail to permit comparison over a wide spectral range. In the present article, the infrared absorption spectra of 20 fully-acetylated pyranoses, in the range of 5000 to $250 \mathrm{~cm}^{-1}$, are given; all of the bands of all of these esters have been measured and have received consideration.

The second objective was the discovery of correlations that might be of value in structural analysis, both as regards (a) the presence of certain functional groups and (b) the particular conformation assumed by each ester. Isbell and coworkers [3] recorded the infrared spectra of 17 of the esters dissolved in suitable solvents, and were able to reach certain conclusions regarding correlations of the kind

Figures in brackets indicate the literature references at the end of this paper The references for table 1 are given at the end of the table. mentioned. However, at the low concentrations they employed, minor bands were absent or difficult to detect. The spectrograms have now been recorded for the solid phase, by use of pellets consisting of crystalline ester suspended in an alkalimetal halide.

In parts II and III of this series [6, 7], a method was described for gaining information regarding the conformations of aldopyranosides and their acetates from analysis of their infrared spectra. The analysis revealed groups of absorption bands, characteristic for each group-configuration, which displayed a concerted shift on change of anomeric disposition. This empirical observation was employed, in conjunction with a consideration of instability factors (arrived at on theoretical grounds), in making conformational assignments and in deciding the arrangement of groups (e.g., axial or equatorial) at the anomeric carbon atom of these compounds. The present article describes the results obtained on applying the same kind of analysis to the infrared spectra of (a) 14 fully-acetylated aldopyranoses related to 13 of the methyl aldopyranosides and to 12 of the acetylated methyl aldopyranosides previously studied, and (b) four esters whose corresponding methyl glycopyranoside or its acetate had not been included in parts II and III. Because of a lack of configurationally related esters, the conformations of two of the acetylated pyranoses could not be determined.

\section{Compounds Investigated}

Table 1 gives a list of the compounds, their code numbers [8], and an index to the spectrograms; the serial number of a compound is the same as the number of its spectrogram. Also included in table 1 are (a) the conformation (where known) of the 
TABLE 1. Compounds measured, stable conformations, and index to spectrograms

\begin{tabular}{|c|c|c|c|c|c|c|c|}
\hline \multirow[b]{2}{*}{ Code a } & \multirow[b]{2}{*}{ Compound } & \multirow[b]{2}{*}{$\begin{array}{l}\text { Refer- } \\
\text { ence }\end{array}$} & \multicolumn{4}{|c|}{ Stable conformation b } & \multirow[b]{2}{*}{$\begin{array}{l}\text { Spectro- } \\
\text { gram }\end{array}$} \\
\hline & & & $\begin{array}{l}\text { Assignment for } \\
\text { methyl glyco- } \\
\text { pyranoside }{ }^{\circ}\end{array}$ & $\begin{array}{l}\text { Assignment for } \\
\text { acetylated methyl } \\
\text { glycoside d }\end{array}$ & $\begin{array}{c}\text { Present } \\
\text { assignment e }\end{array}$ & $\begin{array}{l}\text { Anomeric } \\
\text { disposition e }\end{array}$ & \\
\hline 12. 11121 & Tetra- $O$-acetyl- $\alpha$-D-xylopyranose & 1 & $\mathrm{CA}$ & $\mathrm{CA}_{-}$ & $\mathrm{CA}_{-}$ & & 1 \\
\hline 12. 11221 & Tetra- $O$-acetyl- $\beta$-D-xylopyranose & 1 & CA & $\mathrm{CA}$ & $\mathrm{CA}$ & & 2 \\
\hline 12. 12521 & Tetra- $O$-acetyl- $\alpha$-D-lyxopyranose & 2 & $\mathrm{CA}+\mathrm{CE} ;$ non- & $\mathrm{CA}+\mathrm{CE} ;$ non- & $\mathrm{CA}_{-.}$ & $a_{-.-}$ & 3 \\
\hline 12. 13421 & Tetra- $O$-acetyl- $\alpha$-L-arabinopyranose & 3 & $\mathrm{CE}_{\ldots} \ldots$ & & $\mathrm{CE}_{-}$ & & 4 \\
\hline 12. 71121 & Penta- $O$-acetyl- $\alpha$-L- $x y l o$-hexulopyranose & 4 & & & $\mathrm{CA}_{-}$ & & \\
\hline 12. 21121 & Penta-O-acetyl- $\alpha$-D-glu & 5 & $\mathrm{CA}$ & $\mathrm{CA}^{-1}$ & & & 6 \\
\hline 12. 21221 & Penta- $O$-acetyl- $\beta$-D-glucopyranose & 6 & $\mathrm{CA}$ & $\mathrm{CA}$ & $\mathrm{CA}$ & $e_{-}$ & 7 \\
\hline $\begin{array}{l}\text { 12. } 81121 \\
12.41221\end{array}$ & $\begin{array}{l}\text { Hexa-O-acetyl- } \alpha \text {-D-gluco-heptulopyranose } \\
\text { Hexa-O-acetyl-L-glycero- } \beta \text {-D-gluco-heptopyranose-- }\end{array}$ & $\begin{array}{l}7 \\
8\end{array}$ & & & $\begin{array}{l}\mathrm{CA} \\
\mathrm{CA}+\mathrm{CE} ; \text { non- }\end{array}$ & $a+e ; a, e$, or $q$ & $\begin{array}{l}8 \\
9\end{array}$ \\
\hline 12. $35 ? 21$ & Hexa-O-acety D-glycero- $\beta$-D-ido-heptopyranose_... & 9 & & & chair. & & 10 \\
\hline 12. 22121 & Penta- $O$-acetyl- $\alpha$-D-mannopyrano & 10 & $\mathrm{CA}$ & $\mathrm{CA}$ & & & 1 \\
\hline 12. 2 & Penta- $O$-acetyl- $\boldsymbol{\beta}$-D-mannopyrano & 11 & & $\mathrm{CA}$ & $\mathrm{CA}$. & $e_{-.-}$ & 12 \\
\hline 12. 42121 & Hexa - $O$ - acetyl-D - glycero- $\alpha$-L - manno - hepto- & 12 & $\mathrm{CA}$ & & $\mathrm{CA}_{-}$ & $a_{\ldots}$. & 13 \\
\hline 12. 26521 & $\begin{array}{l}\text { pyranose. } \\
\text { Penta- } O \text {-acetyl- } \alpha \text {-D-gulopyranose } \ldots . .\end{array}$ & 9 & $\mathrm{CA}+\mathrm{CE}$; non- & $\mathrm{CA}+\mathrm{CE}$; non- & $\mathrm{CA}+\mathrm{CE} ;$ non- & $a+e ; a, e$, or $q$ & 14 \\
\hline 12. 36121 & Hexa-O-acetyl-D-glycero- $\alpha$-D-gulo-heptopyranose._ & 13 & CA & $\mathrm{CA}_{\ldots} \ldots$ & $\begin{array}{l}\text { chair. } \\
\text { CA. }\end{array}$ & $a_{\ldots} \ldots$ & 15 \\
\hline 12. 36221 & Hexa- $O$-acetyl-D-glycero- $\beta$-D-gulo-heptopyranose- - & 13 & $\mathrm{CA}_{--}$ & $\mathrm{CA}_{--}$ & $\mathrm{CA}_{-\ldots}$ & & 16 \\
\hline 12. 23121 & Penta- $O$-acetyl- $\alpha$-D-galactopyranose-.. & 14 & CA & $\mathrm{CA}$ & $\mathrm{CA}$ & & 17 \\
\hline $\begin{array}{l}\text { 12. } 23221 \\
\text { 12. } 33521\end{array}$ & $\begin{array}{l}\text { Penta- } O \text {-acetyl } \boldsymbol{\beta} \text {-D-galactopyranose } \\
\text { Hexa - } O \text { - acetyl-D - glycero - } \boldsymbol{\beta} \text { - D - galacto - hepto- }\end{array}$ & $\begin{array}{l}14 \\
15\end{array}$ & $\mathrm{CA}_{-}$ & $\mathrm{CA}$ & CA-CE; non- & $e_{a}+e^{-} a_{0}$ or $q$ & $\begin{array}{l}18 \\
19\end{array}$ \\
\hline & $\begin{array}{l}\text { pyranose. } \\
\text { pyr- }\end{array}$ & & & & chair. & & \\
\hline 12. $24 ? 21$ & Penta- $O$-acetyl- $\alpha$-D-talopyranose & 16 & & & & & 20 \\
\hline
\end{tabular}

a The third figure after the point was inserted after the present conclusions as to conformation had been reached.

b Named by the system of H. S. Isbell and R. S. Tipson, Science 130, 793 (1959); J. Research NBS 64A, 171 (1960).

c Assignment made by R. S. Tipson and H. S. Isbell, J. Research NBS 64 A, 239 (1960).

d Assignment made by R. S. Tipson and H. S. Isbell, J. Research NBS 64A, 405 (1960).

e After accepting several of the assignments for the corresponding unacetylated or acetylated methyl glycopyranosides (see te xt).

\section{References for Table 1}

1. C. S. Hudson and J. M. Johnson, J. Am. Chem. Soc. 37, 2748 (1915).

2. P. A. Levene and M. L. Wolfrom, J. Biol. Chem. 78, 525 (1928).

3. C. S. Hudson and J. K. Dale, J. Am. Chem. Soc. 40, 992 (1918).

5. A. Georg, Helv. Chim. Acta 12, 261 (1929).

6. C. S. Hudson and J. K. Dale, J. Am. Chem. Soc. 37, 1264 (1915).

7. W. C. Austin, J. Am. Chem. Soc. 54, 1925 (1932)

8. H. L. Frush and H. S. Isbell, unpublished results. The optical rotation of H. L. Frush and H. S. Isbell, unpublished results. The optical rotation of
the compound was equal in magnitude, but opposite in sign, to that of its the compound was equal in magnitude, but opposite in sign, to that of its
enantiomorph [R. Hann and C. S. Hudson, J. Am. Chem. Soc. 59, 548 (1937)], and the two compounds had the same melting point
9. H. L. Frush and H. S. Isbell, J. Research NBS 35, 111 (1945) RP1663.

10. C. S. Hudson and J. K. Dale, J. Am. Chem. Soc. 37, 1280 (1915).

11. D. H. Brauns, J. Research NBS 7, 573 (1931) RP358.

12. H. S. Isbell, F. A. Smith, E. C. Creitz, H. L. Frush, J. D. Moyer, and J. E Stewart, J. Research NBS 59, 41 (1957) RP2772.

13. C. S. Hudson and E. Yanovsky, J. Am. Chem. Soc. 38, 1575 (1916).

14. C. S. Hudson and H. O. Parker, J. Am Chem. Soc. 37, 1589 (1915).

15. E. Montgomery and C. S. Hudson, J. Am. Chem. Soc. 56, 2463 (1934).

16. W. W. Pigman and H. S. Isbell, J. Research NBS 19, 189 (1937) RP1021. corresponding methyl glycoside and acetylated methyl glycoside, as determined in parts II and III of this series [6, 7], and (b) assignments of conformations to the acetylated pyranoses. The conformations are indicated by the system devised by Isbell and Tipson [9].

The spectra were measured in the region of 5000 to $250 \mathrm{~cm}^{-1}$. The spectrograms are given together with a discussion of (a) the structure of the compounds and (b) some of the outstanding features of their spectra.

All of the compounds listed in table 1 are fully acetylated monosaccharides, and all have the pyranoid ring. Compounds 5 and 8 are acetates of ketopyranoses; the rest of the compounds are acetates of aldopyranoses. The pyranose acetates differ in regard to one or more of the following structural features: (a) the $\alpha$ or $\beta$ anomeric configuration at the reducing carbon atom; (b) the configurations of the other carbon atoms of the pyranoid ring (including $\mathrm{C} 5$ in the aldohexose and the heptose acetates); (c) the nature of the substituent, if any, at C5 (including the configuration at $\mathrm{C} 6$ of the aldoheptose acetates); and (d) the presence or absence of a $C$-(acetoxymethyl) group at $\mathrm{C} 1$ of the pyranoid ring.

\section{Reference Aldopyranosides and Their Acetates (of Known Conformation)}

In part II of this series, the stable conformations of 13 crystalline aldopyranosides and, in part III, of 12 crystalline acetates thereof, all of which are related to compounds in the present study, were deduced from analysis of their infrared spectra.

In the present study, the crystalline acetates of 14 corresponding pyranoses were available (group A). In addition, six pyranose acetates (group B) whose glycosides or acetylated glycosides had not been available were examined. The spectra of the acetates in group A were analyzed, in order to determine whether they were explicable on the basis that a pyranose acetate has the same conformation as its glycopyranoside and acetylated glycopyranoside relatives. The conclusions drawn from this study were then applied to deducing the stable conformation of members of group B. 


\section{Classification of the Acetylated Pyranoses into Configurationally Related Groups}

The 20 esters were classified into four groups; the members of each group have like configurational features.

\subsection{Acetylated Pyranoses of the xylo Configuration}

The members of this group have general formula I for the CA conformation.

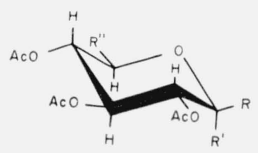

The following compounds, in this conformation, have structure I, with the substituents indicated.

1. Tetra-O-acetyl- $\alpha$-D-xylopyranose, $\quad \mathrm{R}=\mathrm{H} ; \quad \mathrm{R}^{\prime}=$ $\mathrm{OAc}$; and $\mathrm{R}^{\prime \prime}=\mathrm{H}$.

2. Tetra- $O$-acetyl- $\beta$-D-xylopyranose, $R=O A c: R^{\prime}=$ $\mathrm{H}$; and $\mathrm{R}^{\prime \prime}=\mathrm{H}$.

5. Penta-O-acetyl- $\alpha$-L- $x y$ lo-hexulopyranose (penta$O$-acetyl- $\alpha$-L-sorbopyranose), $\mathrm{R}=\mathrm{CH}_{2} \mathrm{OAc} ; \mathrm{R}^{\prime}$ $=\mathrm{OAc} ; \mathrm{R}^{\prime \prime}=\mathrm{H}$; and the molecule is the mirror image of that depicted.

6. Penta- $O$ - acetyl- $\alpha$-D -glucopyranose, $\mathrm{R}=\mathrm{H} ; \mathrm{R}^{\prime}=$ $\mathrm{OAc}$; and $\mathrm{R}^{\prime \prime}=\mathrm{CH}_{2} \mathrm{OAc}$.

7. Penta-O-acetyl- $\beta$-D-glucopyranose, $\mathrm{R}=\mathrm{OAc} ; \mathrm{R}^{\prime}=$ $\mathrm{H}$; and $\mathrm{R}^{\prime \prime}=\mathrm{CH}_{2} \mathrm{OAc}$.

8. Hexa-O-acetyl- $\alpha$-D-gluco-heptulopyranose, $\quad \mathrm{R}=$ $\mathrm{CH}_{2} \mathrm{OAc} ; \mathrm{R}^{\prime}=\mathrm{OAc}$; and $\mathrm{R}^{\prime \prime}=\mathrm{CH}_{2} \mathrm{OAc}$.

9. Hexa - O - acetyl - L - glycero - $\beta$-D - gluco - heptopyranose, $\quad \mathrm{R}=\mathrm{OAc} ; \quad \mathrm{R}^{\prime}=\mathrm{H} ; \quad$ and $\mathrm{R}=$ $\mathrm{AcOH}_{2} \mathrm{C}-\underset{\mathrm{H}}{\mathrm{C}-}$ -

Compound 10 has the following formulas (II) for the two chair-conformations.
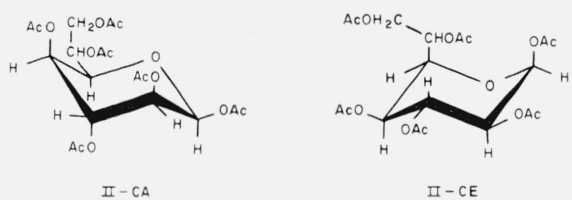

10. Hexa-O-acetyl-D-glycero- $\beta$-D-ido-heptopyranose

\subsection{Acetylated Pyranoses of the 1yxo Configuration}

Four members of this group have the lyxo or manno configuration and general formula III for the CA conformation.

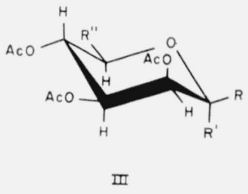

The following compounds, in this conformation, have structure III, with the substituents indicated.

3. Tetra- $O$-acetyl- $\alpha$-D-lyxopyranose, $\mathrm{R}=\mathrm{H} ; \mathrm{R}^{\prime}=$ $\mathrm{OAc}$; and $\mathrm{R}^{\prime \prime}=\mathrm{H}$.

11. Penta- $O$-acetyl- $\alpha$-D-mannopyranose, $\mathrm{R}=\mathrm{H} ; \mathrm{R}^{\prime}=$ $\mathrm{OAc}$; and $\mathrm{R}^{\prime \prime}=\mathrm{CH}_{2} \mathrm{OAc}$.

12. Penta - $O$ - acetyl - $\beta$ - D - mannopyranose, $\mathrm{R}=$ $\mathrm{OAc} ; \mathrm{R}^{\prime}=\mathrm{H}$; and $\mathrm{R}^{\prime \prime}=\mathrm{CH}_{2} \mathrm{OAc}$.

13. Hexa - $O$ - acetyl - D - glycero - $\alpha-\mathrm{L}-$ manno - heptopyranose, $\quad \mathrm{R}=\mathrm{H} ; \quad \mathrm{R}^{\prime}=\mathrm{OAc} ; \quad \mathrm{R}^{\prime \prime}=$ $\mathrm{AcOH}_{2} \mathrm{C}-\underset{\mathrm{OAc}}{\mathrm{C}-}$; and the molecule is the mirror

image of that depicted.

Compounds 14 to 16 have the D-gulo configuration and the following general formula (IV) for the CA conformation.

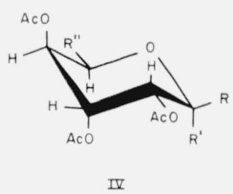

14. Penta- $O$-acetyl- $\alpha$-D-gulopyranose, $\quad \mathrm{R}=\mathrm{H} ; \mathrm{R}^{\prime}=$ $\mathrm{OAc}$; and $\mathrm{R}^{\prime \prime}=\mathrm{CH}_{2} \mathrm{OAc}$.

15. Hexa - $O$ - acetyl - D - glycero - $\alpha$ - D - gulo - heptopyranose, $\mathrm{R}=\mathrm{H} ; \mathrm{R}^{\prime}=\mathrm{OAc}$; and $\mathrm{R}^{\prime \prime}=$ $\mathrm{AcOH}_{2} \mathrm{C}-\underset{\mathrm{OAc}}{\mathrm{C}}-\stackrel{\mathrm{H}}{\mathrm{C}}$.

16. Hexa - $O$ - acetyl - D - glycero - $\beta$ - D - gulo - heptopyranose, $\mathrm{R}=\mathrm{OAc} ; \mathrm{R}^{\prime}=\mathrm{H} ;$ and $\mathrm{R}^{\prime \prime}=$ $\mathrm{AcOH}_{2} \mathrm{C}-\underset{\mathrm{OAc}}{\mathrm{C}-}$.

\subsection{Acetylated Pyranoses of the arabino Con- figuration}

The CE conformation of compound 4 and the CA conformation of compounds 17 to 19 are depicted in general formula $\mathrm{V}$.

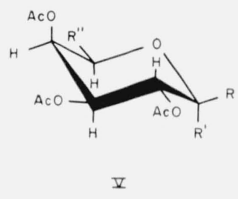

4. Tetra-O-acetyl- $\alpha$-L-arabinopyranose, $\mathrm{R}=\mathrm{OAc}$; $\mathrm{R}^{\prime}=\mathrm{H}$; and $\mathrm{R}^{\prime \prime}=\mathrm{H}$. 
17. Penta - O - acetyl - $\alpha-\mathrm{D}$ - galactopyranose, $\mathrm{R}=\mathrm{H}$; $\mathrm{R}^{\prime}=\mathrm{OAc}$; and $\mathrm{R}^{\prime \prime}=\mathrm{CH}_{2} \mathrm{OAc}$.

18. Penta - $O$ - acetyl - $\beta$ - D - galactopyranose, $\mathrm{R}=$ $\mathrm{OAc} ; \mathrm{R}^{\prime}=\mathrm{H}$; and $\mathrm{R}^{\prime \prime}=\mathrm{CH}_{2} \mathrm{OAc}$.

19. Hexa - $O$ - acetyl - D - glycero - $\beta$ - D - galacto - heptopyranose, $\mathrm{R}=\mathrm{OAc} ; \mathrm{R}^{\prime}=\mathrm{H} ;$ and $\mathrm{R}^{\prime \prime}=$ $\mathrm{AcOH}_{2} \mathrm{C}-\underset{\mathrm{OAc}}{\mathrm{C}-}$.

\subsection{Acetylated Aldopyranose of the ribo Con- figuration}

The two chair-conformations of compound 20 are depicted in formulas VI.
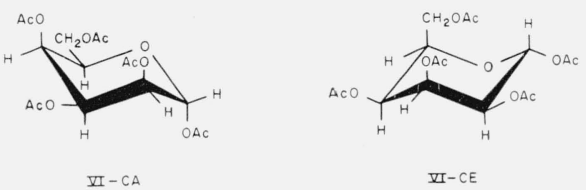

20. Penta-O-acetyl- $\alpha$-D-talopyranose

\section{Discussion of the Spectra}

In the present study, the positions of the various absorption bands for each of 20 acetylated pyranoses have been determined; the relative intensities of absorption were not examined in detail. The bands were compiled, and were studied by comparative methods, as previously described [10].

The conformations of 13 of the corresponding glycopyranosides and of 12 of the acetylated glycopyranosides had previously been assigned by us $[6,7]$ from a study of their infrared absorption spectra (see table 1). Assignment was made on the basis of the empirical observation that a change of anomeric disposition was accompanied by a shift of certain absorption bands.

The same kind of examination has now been applied to the spectra of the fully acetylated derivatives of 14 pyranoses related to the glycosides just mentioned, and a similar empirical relationship (between anomeric disposition and the position of certain absorption bands) was observed. On the basis of this finding, conformational assignments were made for these 14 pyranose acetates and were found to be in essential agreement with those for their glycosidic relatives (both acetylated and unacetylated).

The remaining 6 spectra were those of pyranose acetates for whose glycosidic relatives we had made no conformational assignment. The spectra of four of these acetates (compounds 5, 8, 9, and 19 in table 1) were intercompared with those of related acetates, especially in regard to anomer-differentiating absorption bands, and assignments were made (see table 1). For compounds 10 and 20, the spectra of related acetates were not available, and assignments could not be made.
5.1. Absorption Bands Possibly Indicative of the Disposition of Groups at the Anomeric Carbon Atom of the Tetra-O-acetyl-pentopyranoses

The spectrum of tetra- $O$-acetyl- $\beta$-D-xylopyranose (compound 2) was compared with that of its $\alpha$ anomer (compound 1), in order to determine the effect of changing the anomeric acetoxyl group from equatorial to axial (or vice versa). A comparison was then made with the spectrum of tetra- $O$-acetyl$\alpha$-L-arabinopyranose (compound 4).

In table 2 are listed those bands that are essen-

TABle 2. Bands $\left(\mathrm{cm}^{-1}\right)$ shown by both anomers of tetra-Oacetyl-D-xylopyranose (compounds 1 and 2) and by tetra0 -acetyl- $\alpha-L$-arabinopyranose (4), and positionally corresponding bands of tetra-O-acetyl- $\alpha-D-$ lyxopyranose (3)

\begin{tabular}{c|c|c|c}
\hline \hline \multicolumn{2}{c|}{$\begin{array}{c}\text { Tetra- } O \text {-acetyl-D-xylo- } \\
\text { pyranoses }\end{array}$} & $\begin{array}{c}\text { Tetra- } 0 \text { - } \\
\text { acetyl- } \alpha \text { - } \\
\text { L-arabino- } \\
\text { pyranose }\end{array}$ & $\begin{array}{c}\text { Tetra- } O- \\
\text { acetyl- } \alpha- \\
\text { D-lyxo- } \\
\text { pyranose }\end{array}$ \\
\hline \multirow{2}{*}{1} & 2 & 4 & 3
\end{tabular}

Possibly non-configurational bands

\begin{tabular}{|c|c|c|c|}
\hline 2959 & 2967 & 2976 & 2967 \\
\hline 2915 & 2890 & 2924 & 2899 \\
\hline 2114 & 2114 & 2114 & 2105 \\
\hline 1739 & 1742 & 1736 & 1742 \\
\hline 1473 & 1473 & 1462 & 1484 \\
\hline 1439 & 1437 & 1433 & 1439 \\
\hline 1377 & 1381 & 1374 & 1377 \\
\hline 1230 & 1235 & 1233 & 1227 \\
\hline 1178 & 1172 & 1181 & 1170 \\
\hline 1105 & 1085 & 1096 & 1099 \\
\hline 1046 & 1041 & 1045 & 1052 \\
\hline 1026 & $1028(?)$ & a 1024 & 1021 \\
\hline 989 & 991 & 995 & 985 \\
\hline 965 & 962 & 967 & 963 \\
\hline 947 , а942 & b 941 & b 948 & 946 \\
\hline 899 & b 899 & b 900 & 903,889 \\
\hline 875 & b 880 & b 880 & 885 \\
\hline 679 & 703 & 679 & 690 \\
\hline 673 & 671 & 671 & 670 \\
\hline 643 & 646 & 643 & 647 \\
\hline 601 & 602 & 600 & 599 \\
\hline 567 & 568 & 553 & 556 \\
\hline 545 & 542 & 536 & 534 \\
\hline 515 & 502 & 506 & 508 \\
\hline 488 & 491 & 489 & 488 \\
\hline 398 & 394 & 399 & 395 \\
\hline 372 & 377 & 379 & 379 \\
\hline 365 & 364 & 366 & 369,364 \\
\hline 358 & 359 & 359 & 358 \\
\hline 351 & 353 & 351 & 354 \\
\hline 344 & 342 & 341 & 342 \\
\hline 288 & 309 & 283 & 297 \\
\hline
\end{tabular}

Bands possibly affected by configuration and conformation

\begin{tabular}{|c|c|c|c|}
\hline & & 2874 & \\
\hline 1751 & 1757 & 1751 & \\
\hline 1330 & 1326 & 1332 & \\
\hline 1304 & 1312 & 1309 & 1205 \\
\hline 1261 & 1258 & 1263 & 1290 \\
\hline 1142 & 1130 & 1133 & \\
\hline 1066 & 1071 & 1116 & $\begin{array}{c}1111 \\
1073,1064\end{array}$ \\
\hline a 1016 & 1014 & & a 1009 \\
\hline 930 & 935 & 9 & 929 \\
\hline & & b 865 & 857 \\
\hline & & b 751 & 774 \\
\hline $\begin{array}{l}520 \\
458\end{array}$ & 523 & 457 & -1 \\
\hline $448(?)$ & $\begin{array}{l}459 \\
451(?)\end{array}$ & 458 & 447 \\
\hline $443(?)$ & $444(?)$ & $442(?)$ & \\
\hline $437(?)$ & $436(?)$ & $435(?)$ & \\
\hline $424(?)$ & $423(?)$ & 421 & \\
\hline $\begin{array}{l}404 \\
264\end{array}$ & $\begin{array}{l}402 \\
268\end{array}$ & 274.267 & \\
\hline & & & \\
\hline
\end{tabular}
a These bands were mentioned by R. L. Whistler and L. R. House [4].
b These bands were mentioned by S. A. Barker and coworkers [5]-for the b These bands were mentioned by S. A. Barker
enantiomorphs of the compounds in tables 2 and 3 . 
tially the same for these three esters, together with bands (in about the same positions) shown by tetra$O$-acetyl- $\alpha$-D-lyxopyranose (compound 3 ). Bands shown by all four of these acetates are tentatively assumed to be independent of total configuration, whereas those shown by compounds 1 and 2 but not by both compounds 3 and 4 , or by compounds 3 or 4 but not by compounds 1 and 2, may possibly be affected by configuration.

The bands shown by only one anomer of tetra-Oacetyl-D-xylopyranose are given in table 3, together with corresponding bands of tetra- $O$-acetyl- $\alpha-\mathrm{L}-$ arabinopyranose. The resemblance between compounds 2 and 4 may be noted. If these "anomerdifferentiating"' bands have any relationship to the axial or equatorial disposition of the anomeric acetoxyl group, it may be concluded that compounds 2 and 4 have the same anomeric disposition, whereas that for compound 1 is different. If the assignment previously made [6] for the methyl glycopyranoside corresponding to any one of these three esters is extended to the related pyranose acetate, the conformations of the other two are deducible from the results in table 3. Thus, if the anomeric acetoxyl group of compound 2 is equatorial and that of its $\alpha$ anomer is axial, the results indicate that the anomeric acetoxyl group of tetra-O-acetyl- $\alpha$-L-arabinopyranose is equatorial.

On the other hand, the spectrum of compound 3 , although showing two bands in common with that of compound 2 (see table 3), bears a much greater resemblance to that of compound 1 , suggesting that the crystalline material (3) may have the $\mathrm{CA}$ conformation. If this conclusion is correct, it indicates that the stable conformation of a fully acetylated pyranose need not necessarily be the same as the stable conformation of the corresponding fully acetylated methyl glycopyranoside. Presumably, change from the methoxyl group to the acetoxyl group at carbon atom 1 may result in a sufficiently great alteration in nonbonded attractions and repulsions to cause a change in conformation.

\subsection{Analysis of the Spectra of Groups of Configura- tionally Related Pyranose Acetates, Excluding the Pentopyranose Acetates}

The spectra of penta- $O$-acetyl- $\alpha$-L- $x y l_{0}$-hexulopyranose (compound 5) and hexa-O-acetyl- $\alpha$-D-glucoheptulopyranose (compound 8) were compared with those of the anomers of penta- $O$-acetyl-D-glucopyranose (compounds 6 and 7 ). Compounds 5, 6 , and 8 show the following bands not shown ${ }^{2}$ by compound 7: at 1312 to $1302 \mathrm{~cm}^{-1} ; 1174$ to $1168 \mathrm{~cm}^{-1} ; 960$ to $949 \mathrm{~cm}^{-1} ; 938 \mathrm{~cm}^{-1} ; 746$ to $712 \mathrm{~cm}^{-1} ; 418$ to $413 \mathrm{~cm}^{-1}$; and 395 to $394 \mathrm{~cm}^{-1}$. Compounds 5 and 6 show bands (not shown by compounds 7 and 8) at 1115 to 1111 $\mathrm{cm}^{-1}$ and 556 to $550 \mathrm{~cm}^{-1}$, and compound 6 does not show a band at 606 to $600 \mathrm{~cm}^{-1}$ that is displayed by compounds 5, 7, and 8 ; with these exceptions, these observations indicate that compounds 5 and $8 \mathrm{re}$ -

\footnotetext{
2 Barker and coworkers [5] originally reported bands at 949 and $938 \mathrm{~cm}^{-1}$ for compound 7 . In a private communication from S. A. Barker and R. Stephens (August 12, 1960), we learn that they have since recorded the spectrum of a (August 12, 1960), we learn that they have since recorded the spectrum of
purified sample of compound 7 and find no absorption between 978 and $911 \mathrm{~cm}^{-1}$.
}

TABLE 3. Bands $\left(\mathrm{cm}^{-1}\right)$ shown by only one anomer of the tetra-O-acetyl-D-xylopyranoses (compounds 1 and 2) and by tetra-O-acetyl- $\alpha$-L-arabinopyranose (4), compared with bands for tetra-O-acetyl- $\alpha-D$-lyxopyranose (3)

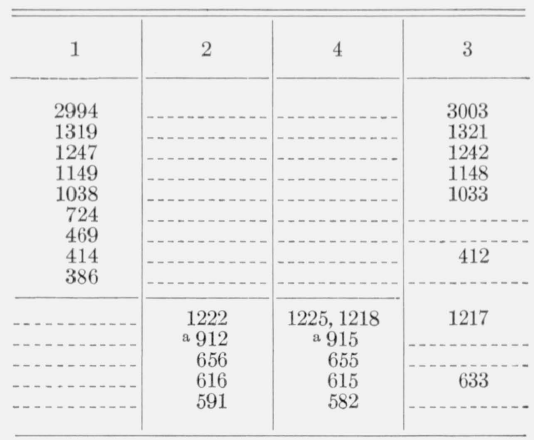

a See footnote $b$ to table 2 .

TABLE 4. Comparison a of absorption bands $\left(\mathrm{cm}^{-1}\right)$ shown by the anomers of penta-O-acetyl-D-glycopyranose (compounds 6 and $\gamma$ ) and by hexa-O-acetyl-L-glycero- $\beta$-D-gluco-heptopyranose (9)

\begin{tabular}{|c|c|c|c|c|c|c|c|}
\hline \multicolumn{2}{|c|}{ A } & B & \multicolumn{2}{|c|}{ C } & $\mathrm{D}$ & \multicolumn{2}{|c|}{$\mathrm{E}$} \\
\hline 6 & 7 & 9 & 6 & 9 & 6 & 7 & 9 \\
\hline $\begin{array}{l}1456 \\
1383\end{array}$ & $\begin{array}{l}1464 \\
1381\end{array}$ & $\begin{array}{c}1215(?) \\
761\end{array}$ & $\begin{array}{r}1115 \\
\text { b } 950\end{array}$ & $\begin{array}{l}1119 \\
955\end{array}$ & $\begin{array}{l}1414 \\
1302\end{array}$ & $\begin{array}{l}600 \\
442\end{array}$ & $\begin{array}{l}597 \\
445\end{array}$ \\
\hline $\begin{array}{l}1105 \\
1062\end{array}$ & $\begin{array}{l}1098 \\
1068\end{array}$ & & $\begin{array}{c}\text { b,o } 938 \\
\text { b }[846\end{array}$ & $\begin{array}{c}941 \\
\text { d } 844]\end{array}$ & 1238 & & \\
\hline 1038 & 1044 & & b 746 & 742 & $\begin{array}{r}1108 \\
550\end{array}$ & & \\
\hline $\begin{array}{r}\text { e } 1022 \\
\text { b } 917\end{array}$ & $\begin{array}{l}1010 \\
\text { b } 913\end{array}$ & & 418 & 422 & 399,395 & & \\
\hline 666 & $654(?)$ & & & & & & \\
\hline $\begin{array}{c}474 \\
434,427\end{array}$ & $\begin{array}{l}475 \\
431\end{array}$ & & & & & & \\
\hline 366 & 368 & & & & & & \\
\hline
\end{tabular}

a Key: A. Bands shown by compounds 6 and 7 , but not by 9 . B. Bands shown by compound 9 , but not by 6 and 7 . C. Bands shown by compounds 6 and 9 , but not by 7 . D. Bands shown by compound 6 , but not by 7 and 9 . E. Bands shown by compounds 7 and 9 , but not by 6 .

E. Bands shown by compoute b to table 3 .

- See footnote a to table 2 .

d Compound 7, in carbon tetrachloride, shows a band at $855 \mathrm{~cm}^{-1}$ [3].

semble compound 6 . Thus, if compound 6 has an axial anomeric (acetoxyl) group, it seems likely that compounds 5 and 8 also have an axial anomeric acetoxyl group and, consequently, have an equatorial acetoxymethyl group attached to C1 of the xylopyranose ring.

The spectrum of hexa- $O$-acetyl-L-glycero- $\beta$-D-glucoheptopyranose (compound 9) was now compared with those of compounds 6 and 7 . The results are given in table 4 , from which it may be seen that compounds 6 and 9 have 5 bands in common (column C) that are not shown by compound 7 . On the other hand, compounds 7 and 9 show 2 bands (column E) not shown by compound 6 , and compound 6 shows 6 bands (column D) not shown by compounds 7 and 9. These results indicate about equal similarity between compounds 7 and 9 as between compounds 6 and 9 , and, hence, suggest either (a) that compound 9 adopts a non-chair conformation or a mixture of the $\mathrm{CA}$ and $\mathrm{CE}$ conformations, or (b) that, in this kind of analysis, the spectrum of a fully acetylated heptopyranose may not necessarily be intercomparable with those of the related hexopyranose acetates. 
Penta- $O$-acetyl- $\beta$-D-mannopyranose and hexa- $O$ acetyl - D - glycero - $\alpha$ - L - manno-heptopyranose (compounds 12 and 13) show two bands (at 3003 to 2985 $\mathrm{cm}^{1-}$ and at 616 to $615 \mathrm{~cm}^{-1}$ ) that are not shown by penta- $O$-acetyl- $\alpha$-D-mannopyranose (compound 11). On the other hand, compounds 11 and 13 show seven bands that are not shown by compound 12: at 1295 to $1294 \mathrm{~cm}^{1-}, 1081$ to $1076 \mathrm{~cm}^{-1}, 839$ to $837 \mathrm{~cm}^{-1}, 787$ to $777 \mathrm{~cm}^{-1}, 475$ to $466 \mathrm{~cm}^{-1}, 439$ to $433 \mathrm{~cm}^{-1}$, and 414 to $413 \mathrm{~cm}^{-1}$; and compound 12 shows 12 bands that are not shown by compounds 11 and 13: at 2882,1383, 1093, 758 (this band was mentioned by Barker and coworkers [5]), 589, 520,488,446, 407, 377, 364, and $345 \mathrm{~cm}^{-1}$. These results indicate a considerable resemblance between compounds 11 and 13 . Thus, if the anomeric acetoxyl group of compound 11 is axial, it seems likely that the anomeric acetoxyl group of hexa-O-acetyl-D-glycero- $\alpha$-L-manno-heptopyranose (13) is also axial.

In parts II and III of this series [6,7], evidence was obtained that indicated that the methyl glycopyranosides and their acetates corresponding to the $\alpha$ and $\beta$ anomers of hexa- $O$-acetyl-D-glycero-D-guloheptopyranose (15 and 16 ; see table 1 ) have the CA conformation, whereas those corresponding to penta- $O$-a cetyl- $\alpha$-D-gulopyranose (compound 14) consist of a mixture of the CA and CE conformations or adopt a non-chair conformation. In table $5,^{3}$ the anomer-differentiating bands of compounds 15 and 16 are compared with bands shown by compound 14 . It may be seen that compound 14 shows about equal similarity to either compound 15 or 16 ; this conclusion suggests that crystalline penta- $O$-acetyl- $\alpha$-Dgulopyranose (compound 14) exists as a mixture of the $\mathrm{CA}$ and $\mathrm{CE}$ conformations or as a non-chair conformation.

Finally, an assignment of conformation was sought for hexa-O-acetyl-D-glycero- $\beta$-D-galacto-heptopyranose (compound 19). In table 6 , the bands differentiating between penta- $O$-acetyl- $\alpha$-D-galactopyranose (compound 17) and its $\beta$ anomer (compound 18) are compared with bands for compound 19. It may be seen that compound 19 shows about equal similarity to either compound 17 or 18 , suggesting that crystalline hexa-O-acetyl-D-glycero- $\beta$-D-galacto-heptopyranose (compound 19) exists as a mixture of the CA and CE conformations or as a non-chair conformation. This conclusion is surprising, as there has hitherto been no indication of such conformations for compounds having a galacto configuration. Possibly, as previously mentioned, the spectrum of a fully acetylated heptopyranose may not, in this kind of analysis, necessarily be intercomparable with those of the related hexopyranose acetates.

No assignment could be made for hexa- $O$-acetyl-Dglycero- $\beta$-D-ido-heptopyranose (compound 10), because of the lack of its $\alpha$ anomer. Similarly, no assignment could be made for penta- $O$-acetyl- $\alpha$-D-talopyranose (compound 20), because of a lack of other pyranose acetates having the talo configuration.

\footnotetext{
3 To conserve space, bands which do not differentiate between anomers have
} been omitted from tables 5 and 6 .
TABLE 5. Bands $\left(\mathrm{cm}^{-1}\right)$ shown a by only one anomer of hexaO-acetyl-D-glycero-D-gulo-heptopyranose (compounds 15 and 16), compared with bands for penta-O-acetyl- $\alpha$-D-gulopyranose (14)

\begin{tabular}{|c|c|c|c|c|c|}
\hline \multicolumn{2}{|c|}{ A } & \multirow{2}{*}{$\begin{array}{c}\mathrm{B} \\
16\end{array}$} & \multicolumn{2}{|c|}{$\mathrm{C}$} & \multirow{2}{*}{$\begin{array}{r}\mathrm{D} \\
15\end{array}$} \\
\hline 14 & 15 & & 14 & 16 & \\
\hline \multirow{8}{*}{$\begin{array}{r}1462 \\
1304 \\
1114 \\
994 \\
952 \\
884 \\
816 \\
477\end{array}$} & \multirow{8}{*}{$\begin{array}{r}1453 \\
1304 \\
1114 \\
983 \\
952 \\
887 \\
829 \\
452\end{array}$} & \multirow{8}{*}{$\begin{array}{r}3003 \\
1280 \\
1205 \\
1105 \\
1030 \\
848 \\
523 \\
444\end{array}$} & 2941 & \multirow{7}{*}{$\begin{array}{r}2941 \\
1443 \\
1319 \\
1186 \\
1130 \\
899 \\
766\end{array}$} & 1366 \\
\hline & & & 1443 & & $\begin{array}{l}1000 \\
1064\end{array}$ \\
\hline & & & 1318 & & 781 \\
\hline & & & b 1170 & & 718 \\
\hline & & & 1139 & & \\
\hline & & & 903 & & \\
\hline & & & 769 & & \\
\hline & & & & & \\
\hline
\end{tabular}

a Key: A. Bands shown by compounds 14 and 15 , but not by 16 . B. Bands shown by compound 16 , but not by 14 and 15 . C. Bands shown by compounds 14 and 16 , but not by 15 . D. Bands shown by compound 15 , but not by 14 and 16.

See footnote a to table 2 .

TABLE 6. Comparison a of absorption bands $\left(\mathrm{cm}^{-1}\right)$ shown by the penta-O-acetyl-D-galactopyranoses (compounds 17 and 18) and by hexa-O-acetyl-D-glycero- $\beta$-D-galacto-heptopyranose (19)

\begin{tabular}{|c|c|c|c|}
\hline \multicolumn{2}{|c|}{ A } & \multicolumn{2}{|c|}{ B } \\
\hline 17 & 19 & 18 & 19 \\
\hline $\begin{array}{r}1779 \\
1250 \\
1133 \\
837 \\
696 \\
615\end{array}$ & $\begin{array}{r}1770 \\
1252 \\
\mathrm{~b} 1131 \\
832 \\
700 \\
610\end{array}$ & $\begin{array}{r}1156 \\
\text { b } 1122 \\
1068 \\
\text { c } 916 \\
\text { c } 869 \\
641 \\
575 \\
366\end{array}$ & $\begin{array}{r}1155 \\
1124 \\
1065 \\
927 \\
873 \\
641 \\
573 \\
370\end{array}$ \\
\hline
\end{tabular}

a Key: A. Bands shown by compounds 17 and 19 , but not by 18 . B. Bands shown by compounds 18 and 19 , but not by 17

b See footnote a to table 2 .

S See footnote a to table 2 .

From a study of the proton magnetic-resonance spectra of compounds 1 to $4,6,7,11,12,14,17$, and 18, Lemieux and coworkers [11] made exactly the same assignments of anomeric disposition as we now find for these compounds (see table 1).

Many of the bands observed for the pyranose acetates cannot yet be assigned to particular vibrational modes; in sections 5.1 and 5.2 , we have not been concerned with (a) which bands, arising from vibrations localized in a functional group, are relatively independent of the remainder of the molecule, or (b) which bands involve other parts of the molecule. Bands possibly attributable to specific functional groups are considered in section 5.3.

\subsection{Other Absorption Bands}

All of the compounds in this study are acetates, and their spectra all show at least one band at 1757 to $1742 \mathrm{~cm}^{-1}(\mathrm{C}=\mathrm{O}$ stretching frequency); at 1269 to $1241 \mathrm{~cm}^{-1}$; at 1236 to $1212 \mathrm{~cm}^{-1}$; at 646 to 626 $\mathrm{cm}^{-1}$; and at 612 to $598 \mathrm{~cm}^{-1}$. All of the spectra show at least one band at 2985 to $2950 \mathrm{~cm}^{-1}$ (or 2976 to $2941 \mathrm{~cm}^{-1} ; \mathrm{C}-\mathrm{H}$ stretching); and at 1449 to $1420 \mathrm{~cm}^{-1}$ and 1333 to $1312 \mathrm{~cm}^{-1}$ (C-H bending). All of the spectra show an absorption band at 1381 to $1366 \mathrm{~cm}^{-1}$, presumably caused by deformation of the $\mathrm{CH}_{3}$ groups. All of the spectra also show a 


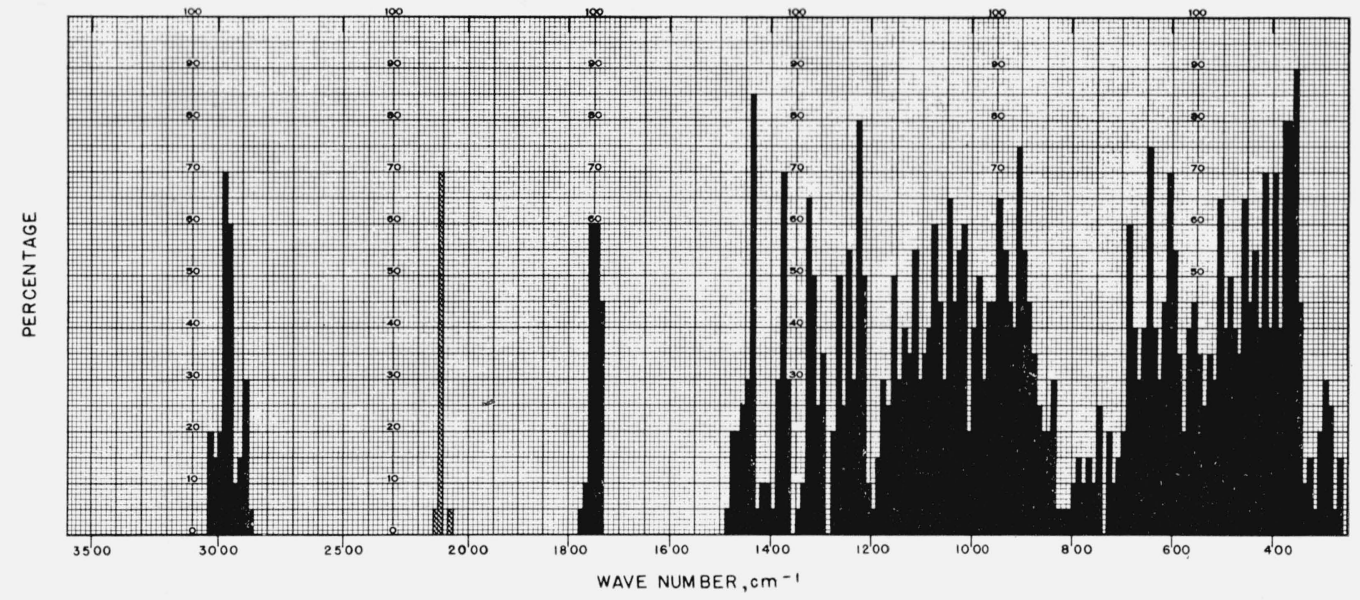

FIGURE 1. Percentage (of the 20 pyranose acetates) which showed infrared absorption at the various regions of the infrared spectrum $\left(5000\right.$ to $\left.250 \mathrm{~cm}^{-1}\right)$.

band at 1148 to $1114 \mathrm{~cm}^{-1} ; 1105$ to $1073 \mathrm{~cm}^{-1}$; 1073 to $1042 \mathrm{~cm}^{-1} ; 1036$ to $1011 \mathrm{~cm}^{-1} ; 911$ to 899 $\mathrm{cm}^{-1}$; 415 to $399 \mathrm{~cm}^{-1}$; and 377 to $366 \mathrm{~cm}^{-1}$ (or 370 to $\left.353 \mathrm{~cm}^{-1}\right)$. All of the spectra seem to show a weak band at 2132 to $2075 \mathrm{~cm}^{-1}$, probably a combination or overtone.

Figure 1 gives the percentage of the 20 acetates in this study that show absorption bands in the various regions of the infrared spectrum. For the range of 5000 to $2000 \mathrm{~cm}^{-1}$, decrements of $20 \mathrm{~cm}^{-1}$ were used; and, for the range of 2000 to $250 \mathrm{~cm}^{-1}$, decrements of $10 \mathrm{~cm}^{-1}$.

\section{Experimental Procedure}

\subsection{Preparation and Purification of the Compounds}

The compounds listed in table 1 were prepared by the methods given in the references cited. Most of the compounds were prepared in the course of earlier studies on the pyranose acetates. Each acetate was recrystallized from an appropriate solvent until further recrystallization caused no change in its melting point or optical rotation.

\subsection{Preparation of the Pellets}

Samples used for photometric study consisted of pellets comprising the crystalline acetate suspended in an alkali-metal halide, exactly as previously described [10]. For the range of 5000 to $667 \mathrm{~cm}^{-1}$, a concentration of $0.4 \mathrm{mg}$ of acetate per $100 \mathrm{mg}$ of potassium chloride was used; the spectrum of compound 2 was also recorded for a film prepared on the sodium chloride window by evaporation of a carbon tetrachloride solution of the compound with a heat lamp. For the range of 667 to $250 \mathrm{~cm}^{-1}$, a concentration of $2 \mathrm{mg}$ of acetate per $100 \mathrm{mg}$ of potassium iodide was used, except for compounds 8 and 9 (3 $\mathrm{mg}$ per $100 \mathrm{mg})$.

\subsection{Measurement of Infrared Absorption}

The spectrograms ${ }^{4}$ are shown in figures 2 and 3 ;

${ }^{4} \mathrm{~A}$ few bands that show clearly in the original spectrograms are difficult to see in the published spectra, because of the reduction in size. they were recorded with a Perkin-Elmer Model 21 (double-beam) spectrophotometer equipped with a prism of sodium chloride (for the range of 5000 to $667 \mathrm{~cm}^{-1}$ ) and of cesium bromide (for the range of 667 to $250 \mathrm{~cm}^{-1}$ ), as previously described [10].

Some absorption attributable to water (in the compound, the alkali halide, or both) was observed at 3448 and $1639 \mathrm{~cm}^{-1}$ and, attributable to atmospheric water vapor, in the far-infrared curves. These regions are drawn on the spectrograms with dashed lines which are not to be interpreted quantitatively.

\subsection{Spectra Measured Under Different Conditions}

The spectra of 17 of the pyranose acetates (compounds 1 to 7 and 10 to 19 ) had previously been measured [3] in carbon tetrachloride or chloroform and in either carbon disulfide or dioxane. Since the infrared absorption spectra of crystalline materials show more bands than the spectra of the same compounds in solution, a larger number of bands were available for correlations than in the previous study [3].

In addition, the spectra of 13 acetylated aldopyranosides had been recorded for the solid phase [7] and for solutions [3]. The spectra for the solid and the liquid phases of these 30 compounds are, in all cases, in striking agreement (after making allowance for the sharpening of the bands for the crystalline samples). This observation suggests that, if the geometry of the molecule is reflected in its vibration spectrum, each of these compounds adopts the same conformation(s) in the solid phase as it does in solution.

The authors express their gratitude to H. L. Frush for assistance in preparing the compounds used in this study, and to J. E. Stewart and F. P. Czech for recording the infrared absorption spectra. 

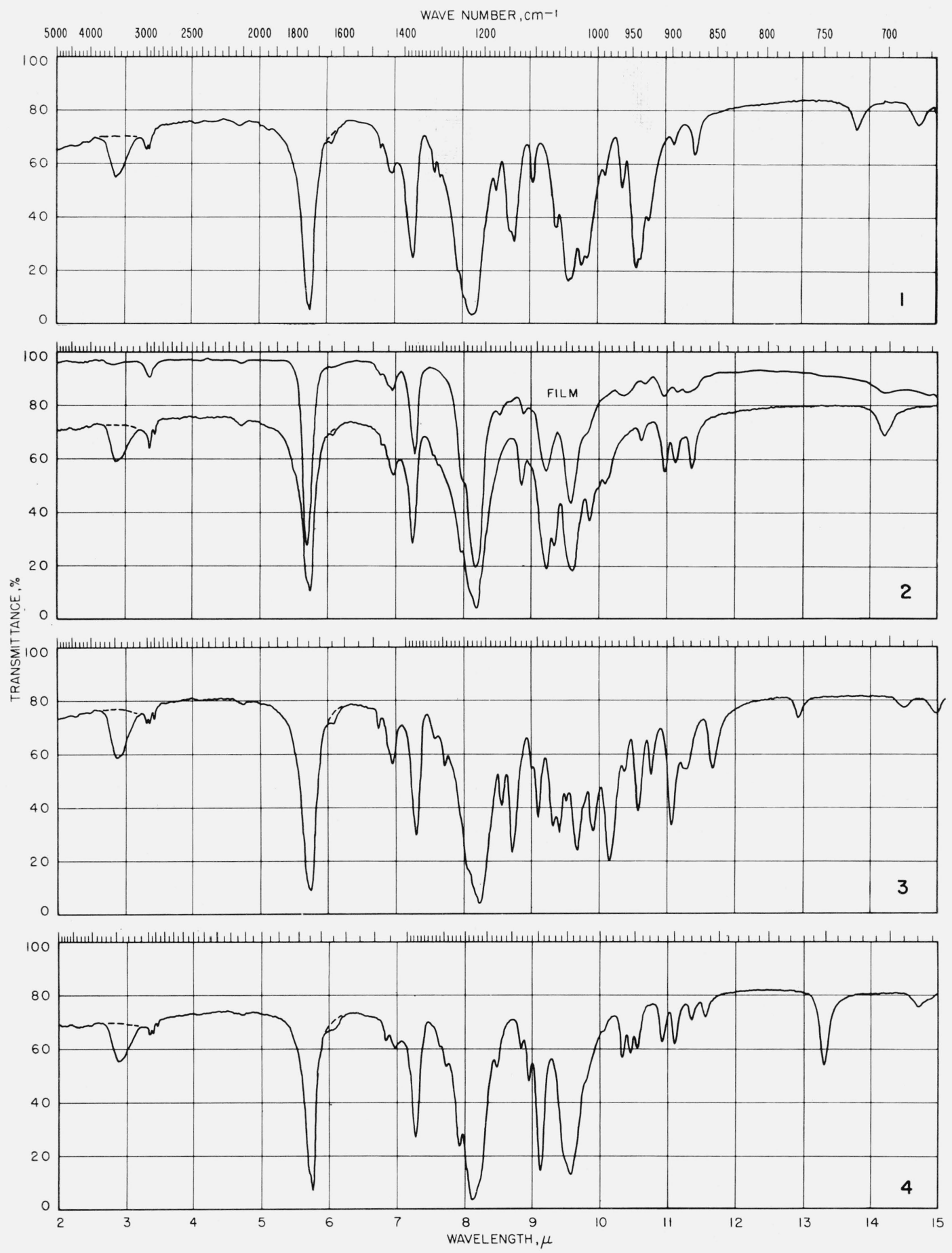

Figure 2. Spectrograms of materials in potassium chloride pellets.

$\mathbf{1}$, Tetra- $O$-acetyl- $\alpha$-D-xylopyranose; 2 , tetra- $O$-acetyl- $\beta$-D-xylopyranose; 3 , tetra- $O$-acetyl- $\alpha$-D-lyxopyranose; $\mathbf{4}$, tetra- $O$-acetyl- $\alpha$-L-arabinopyranose. 

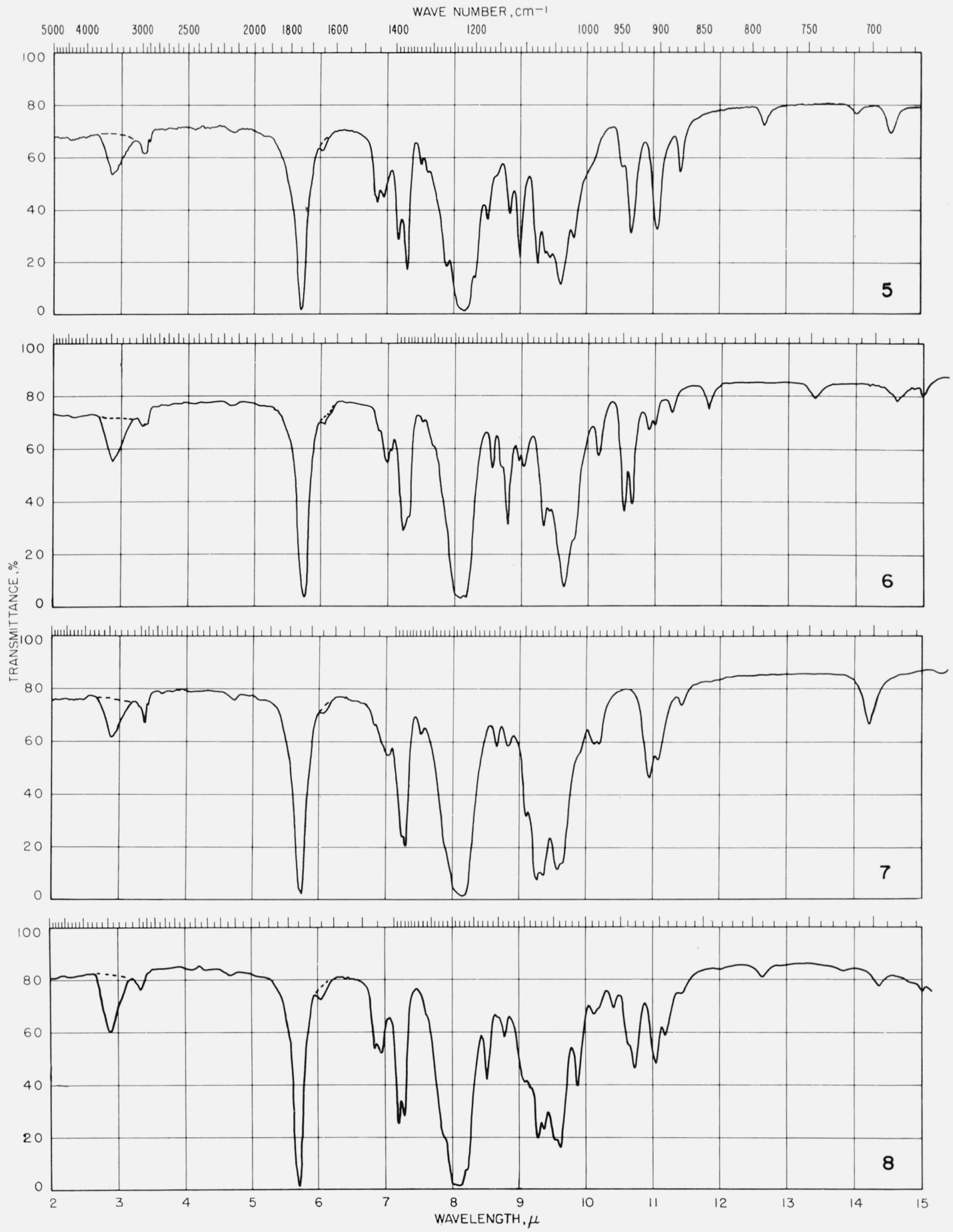

Figure 2. Spectrograms of materials in potassium chloride pellets.-Continued

5, penta- $O$-acetyl- $\alpha$-L-xylo-hexulopyranose; 6, penta- $O$-acetyl- $\alpha$-D-glucopyranose; $\boldsymbol{7}$, penta- $O$-acetyl- $\beta$-D-glucopyranose; 8 , hexa- $O$-acetyl- $\alpha$-D-gluco-heptulopyranose. 

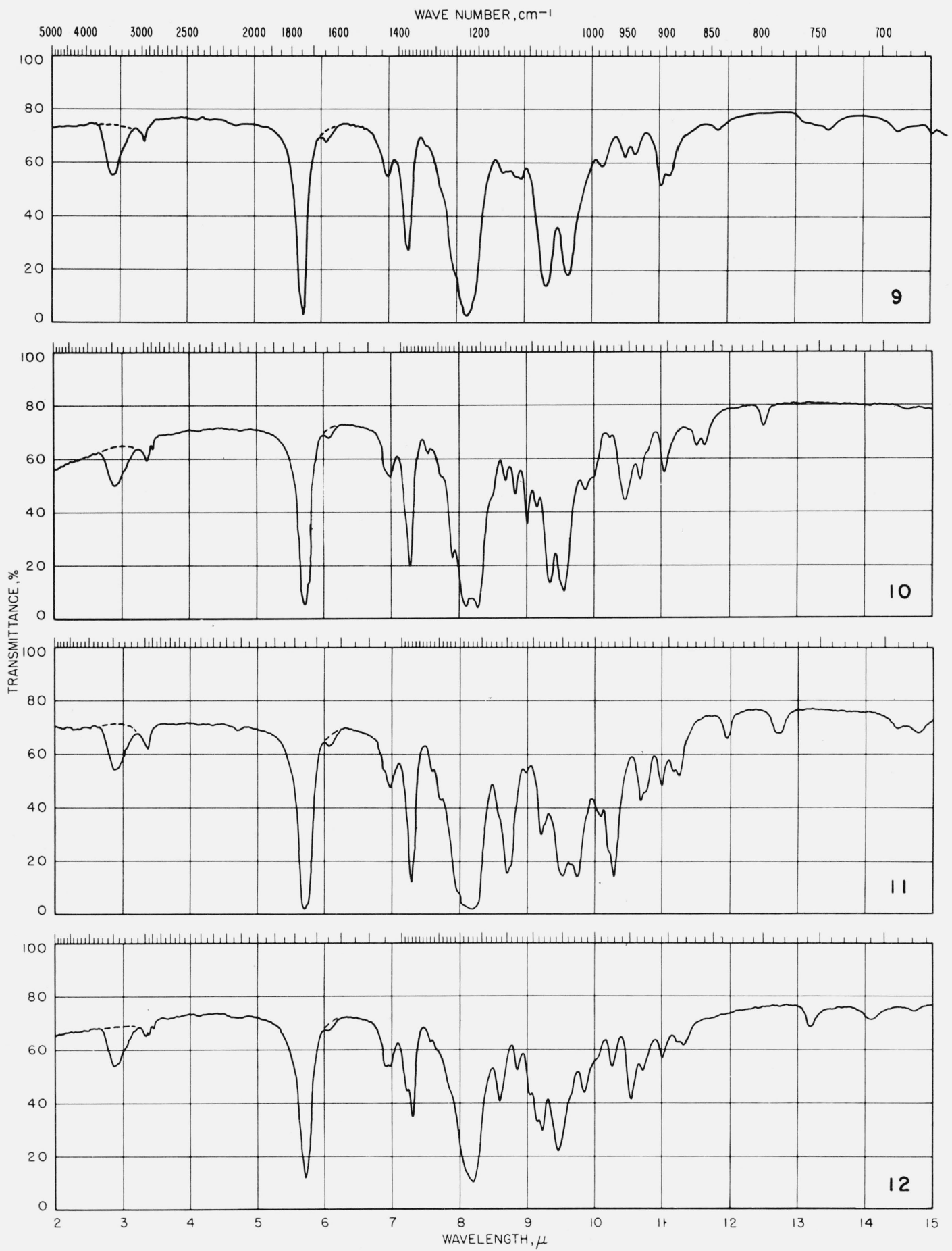

FIGURE 2. Spectrograms of materials in potassium chloride pellets.-Continued

9, hexa-O-acetyl-L-glycero- $\beta$-D-gluco-heptopyranose; 10, hexa-O-acetyl-D-glycero- $\beta$-D-ido-heptopyranose; 11, penta- $O$-acetyl- $\alpha$-D-mannopyranose; 12 , penta- $O$-acetyl$\beta$-D-mannopyranose.

258 

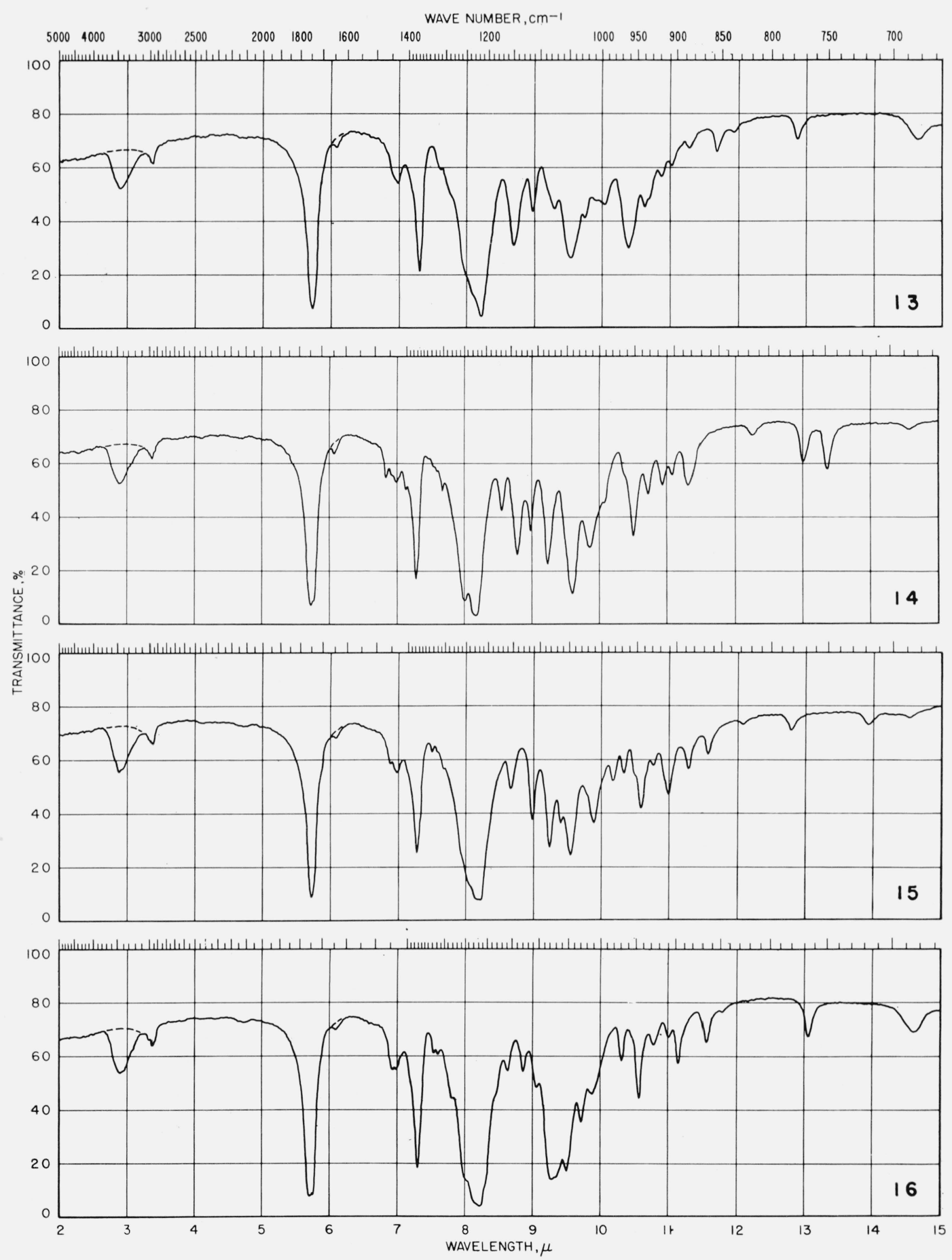

Figure 2. Spectrograms of materials in potassium chloride pellets.-Continued

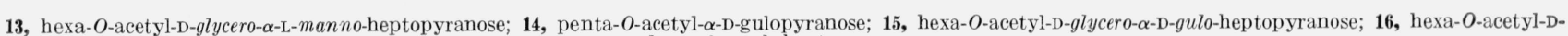
glycer $0-\beta$-D-gulo-heptopyranose. 

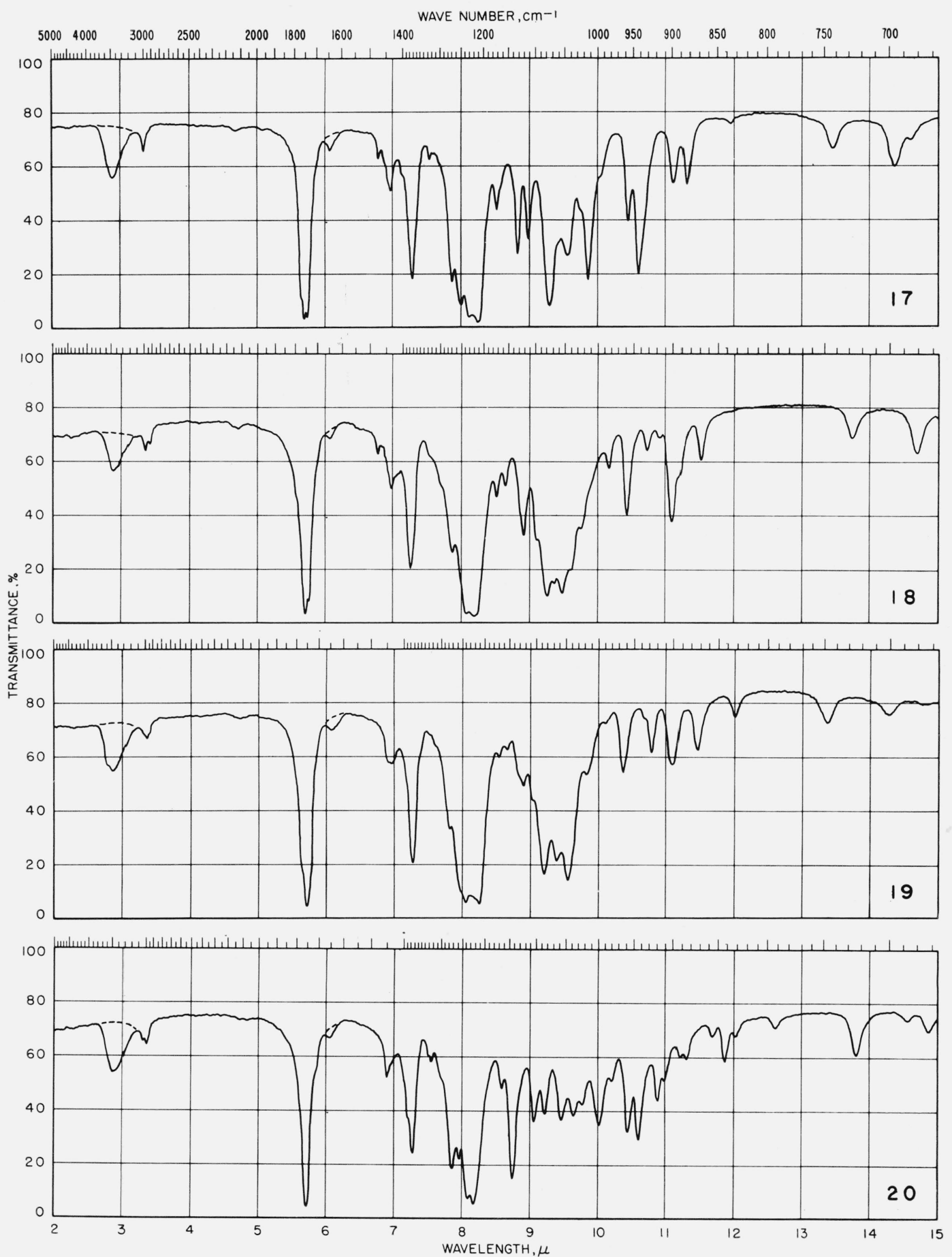

Figure 2. Spectrograms of materials in potassium chloride pellets.-Continued $\mathbf{1 7}$, penta- $O$-acetyl- $\alpha$-D-galactopyranose; 18, penta- $O$-acetyl- $\beta$-D-galactopyranose; $\mathbf{1 9}$, hexa- $O$-acetyl-D-glycero- $\boldsymbol{\beta}$-D-galacto-heptopyranose; $\mathbf{2 0}$, penta- $O$-acetyl- $\alpha$-D-
talopyranose. 

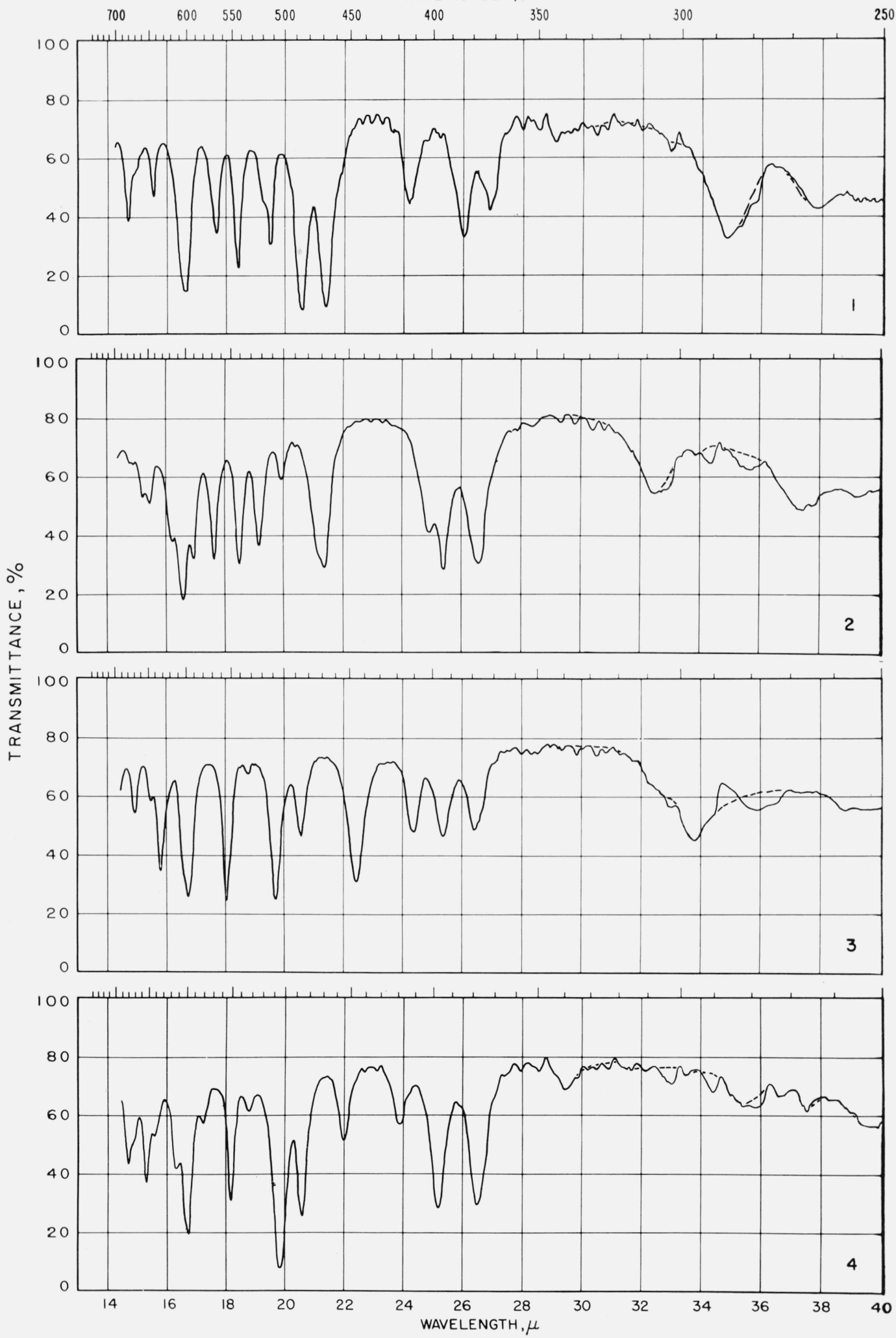

FIGURE 3. Spectrograms of materials in potassium iodide pellets.

1, Tetra- $O$-acetyl- $\alpha$-D-xylopyranose; 2 , tetra- $O$-acetyl- $\beta$-D-xylopyranose; 3, tetra- $O$-acetyl- $\alpha$-D-lyxopyranose; $\mathbf{4}$, tetra- $O$-acetyl- $\alpha$-L-arabinopyranose. 

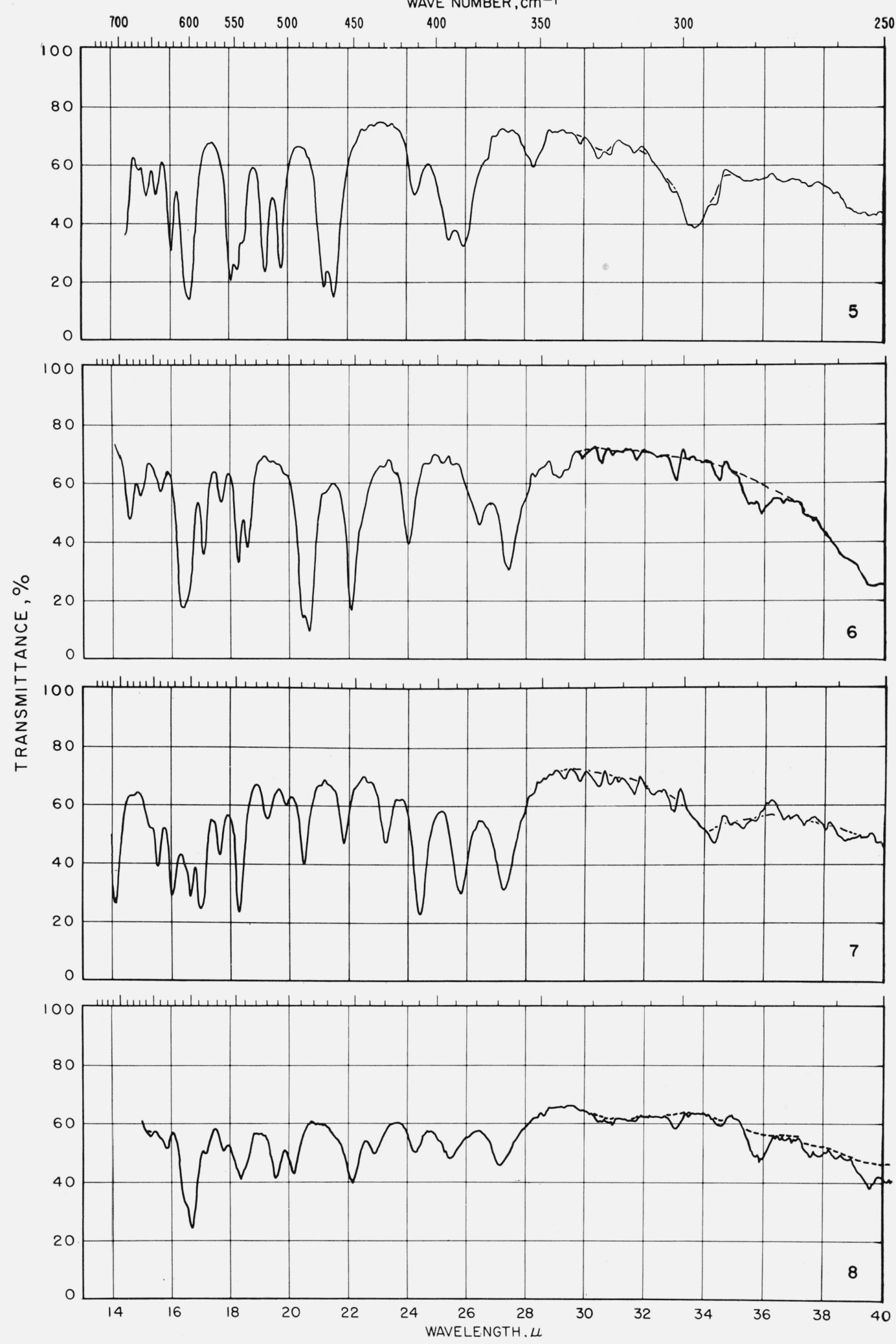

FIGURE 3. Spectrograms of materials in potassium iodide pellets.-Continued

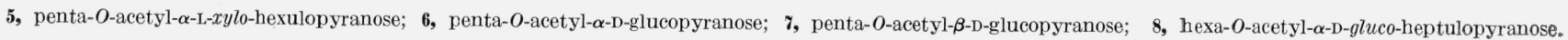



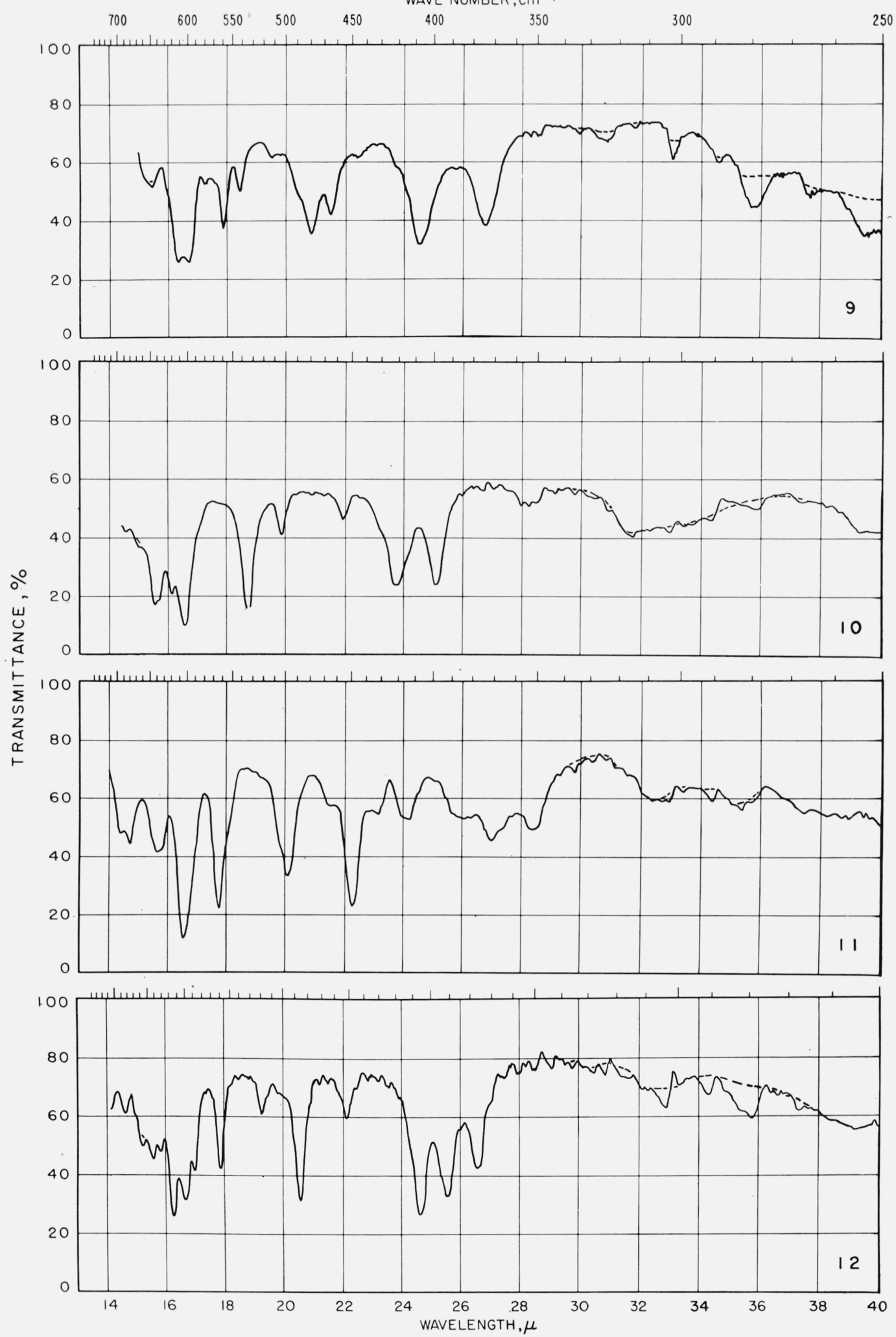

FIGURE 3. Spectrograms of materials in potassium iodide pellets.-Continued

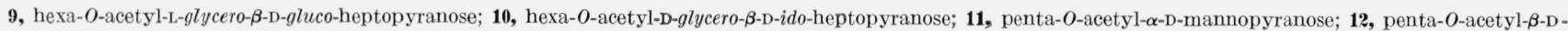
mannopyranose. 

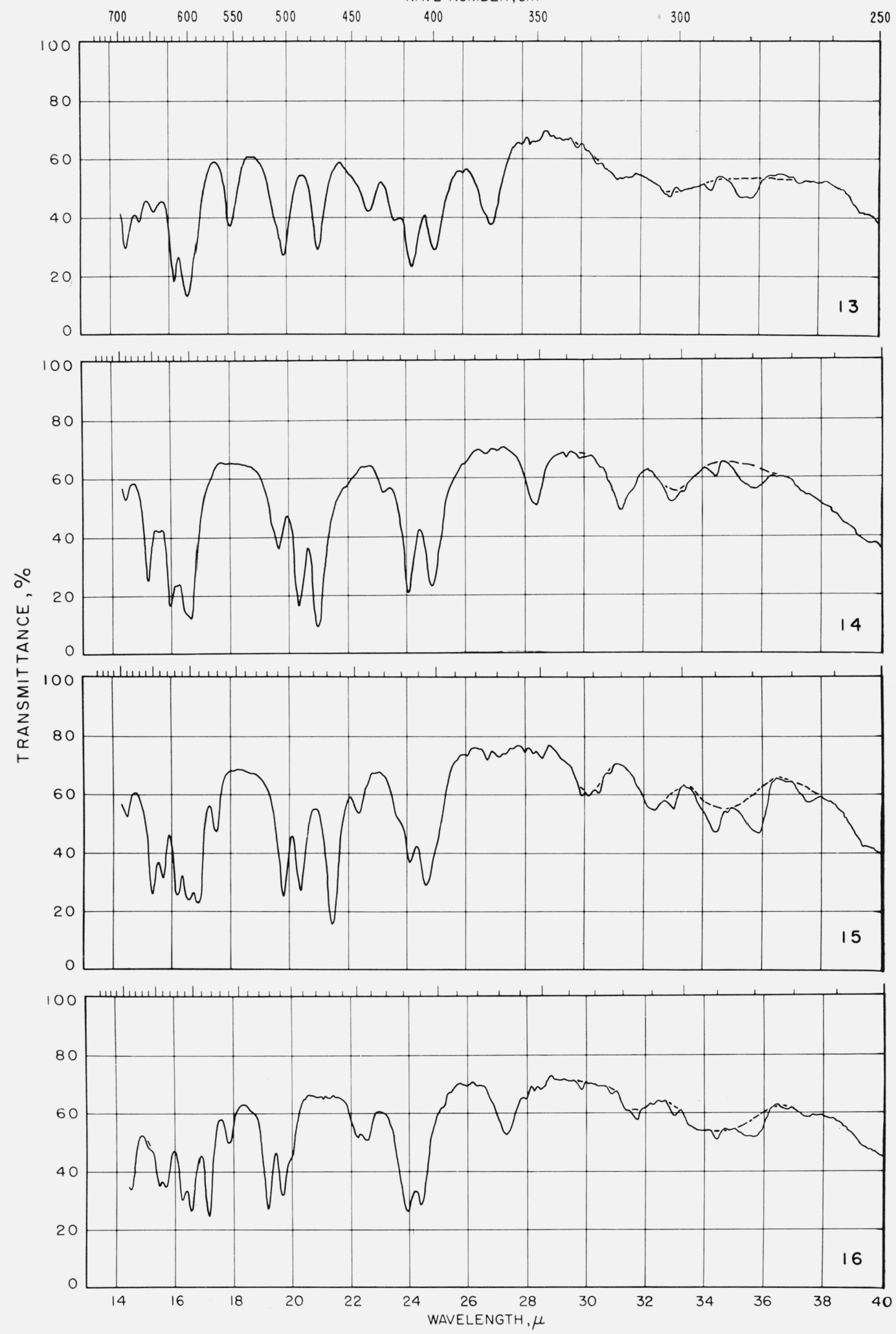

FIGURE 3. Spectrograms of materials in potassium iodide pellets.-Continued

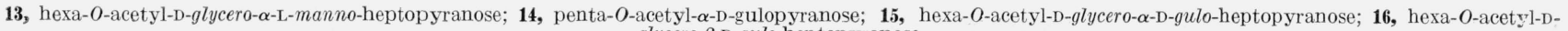
glycero- $\beta$-D-gulo-heptopyranose. 
WAVE NUMBER, $\mathrm{cm}^{-}$
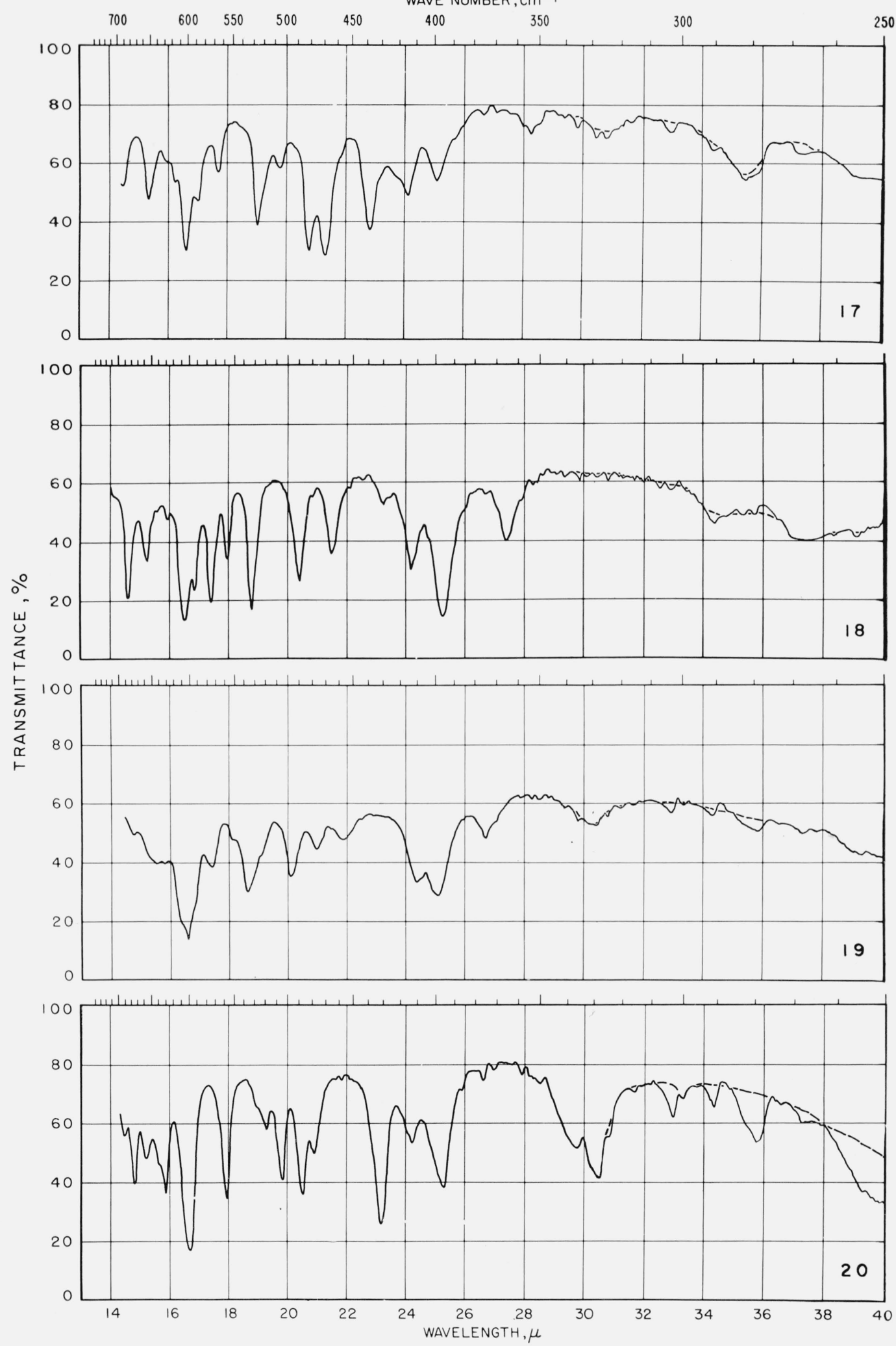

FIGURE 3. Spectrograms of materials in potassium iodide pellets.-Continued

17, penta- $O$-acetyl- $\alpha$-D-galactopyranose; 18, penta- $O$-acetyl- $\beta$-D-galactopyranose; $\mathbf{1 9}$, hexa- $O$-acetyl-D-glycero- $\beta$-D-galacto-heptopyranose; 20 , penta- $O$-acetyl- $\alpha$-Dtalopyranose 


\section{References}

[1] L. P. Kuhn, Anal. Chem. 22, 276 (1950).

[2] H. S. Isbell, F. A. Smith, C. Creitz, J. D. Moyer, and H. L. Frush, Infrared spectra of sugar acetates and related compounds (informal communication).

[3] H. S. Isbell, F. A. Smith, E. C. Creitz, H. L. Frush, J. D. Moyer, and J. E. Stewart, J. Research NBS 59,, 41 (1957) RP2772.

[4] R. L. Whistler and L. R. House, Anal. Chem. 25, 1463 (1953).

[5] S. A. Barker, E. J. Bourne, R. Stephens, and D. H. Whiffen, J. Chem. Soc. 1954, 3468.
[6] R. S. Tipson and H. S. Isbell, J. Research NBS 64A, 239 (1960).

[7] R. S. Tipson and H. S. Isbell, J. Research NBS 64A, $405(1960)$.

[8] H. S. Isbell, J. Research NBS 57, 171 (1956) RP2707.

[9] H. S. Isbell and R. S. Tipson, J. Research NBS 64A, 171 (1960)

[10] R. S. Tipson, H. S. Isbell, and J. E. Stewart, J. Research NBS 62, 257 (1959) RP2960.

[11] R. U. Lemieux, R. K. Kullnig, H. J. Bernstein, and W. G. Schneider, J. Am. Chem. Soc. 80, 6098 (1958).

(Paper 65A3-109) 